\title{
Pressure Loss and Hold-up Powders for Gas-Powder Two Phase Flow in Packed Beds
}

\author{
Koichiro SHIBATA, Masakata SHIMIZU, Shin-ichi INABA, Reijiro TAKAHASHI') and Jun-ichiro YAGI1)
}

Iron \& Steel Research Laboratories, Kobe Steel, Ltd., Wakinohama-cho, Chuo-ku, Kobe, Hyogo-ken, 651 Japan.

1) Research Institute of Mineral Dressing and Metallurgy, Tohoku University, Katahira, Aoba-ku, Sendai, Miyagi-ken, 980 Japan.

(Received on November 5, 1990; accepted in the final form on January 25, 1991)

\begin{abstract}
Flow characteristics of gas-powder two phase flow in packed beds were experimentally examined for clarifying the aerodynamic behavior of powders in a blast furnace. It was found that two phase flow showed higher pressure loss compared with clean gas flow. Based on the experimental results, a mathematical model for gas-powder two phase flow in packed beds was developed. In this model, three kinds of interaction forces were considered, including:

1) the interaction force between gas and packed particles $\left(F_{g-b}\right)$

2) the interaction force between gas and powders $\left(F_{g-p}\right)$, and

3) the restraint force of powder motion due to (i) the gravitational force of powders and (ii) the collision and the friction between powders and packed particles $\left(F_{p-k}\right)$.

$F_{g-b}$ could be given by the Ergun type gas flow resistance, and $F_{g-p}$ could be expressed by the Stokes flow law and the Richardson-Zaki's voidage function. Finally, $F_{p-k}$ could be empirically correlated by using the Fanning equation and the Froude number. This model allows satisfactory prediction of the pressure loss and the hold-up of powders in the packed bed. Furthermore, it was confirmed that the increase in the pressure loss was mainly caused by the increase in the holdup of powders in the region of low gas velocity and by the interaction force between powders and packed particles in the region of high gas velocity.
\end{abstract}

KEY WORDS: ironmaking; blast furnace; packed bed; cold model experiment; gas-powder two phase flow; mathematical model; blockade.

\section{Introduction}

High pulverized coal injection into a blast furnace has gained worldwide attention for the reduction of energy costs. If a large amount of pulverized coal (PG) are injected into a blast furnace, much powder will be generated in the raceway because of the incomplete combustion of PG and the coke degradation. These powders will be transported by gas (gas-powder two phase flow ${ }^{1-6)}$ and enter the packed bed. It is believed that they might considerably affect the permeability in the furnace due to their local deposition. In order to realize high $\mathrm{PC}$ operation, it is important to estimate the flow characteristics of powders in the packed bed quantitatively and to properly maintain the permeability.

In this study, flow characteristics of gas-powder two phase flow were experimentally investigated and theoretically analyzed for clarifying the aerodynamic behavior of powders in a blast furnace.

\section{Experiment}

\subsection{Experimental Apparatus}

The experimental apparatus is illustrated in Fig. 1. This column is made of a straight acrylic resin pipe which has an inner diameter of $100 \mathrm{~mm}$ and a height of $1000 \mathrm{~mm}$. The taps for the measurement of static pressure are located along the column at intervals of $100 \mathrm{~mm}$. The powders are transported by nitrogen gas and introduced into the lower part of the column. The feed rate for powders is controlled by the screw feeder. The powders are separated from exhaust gas by the cyclone.

\subsection{Experimental Procedure}

In the experiment, the glass beads are, at first, packed in the column. Then the glass powders and nitrogen gas are injected into the lower part of the packed bed. The characteristics of the glass beads and the glass powders are listed in Table 1. The static pressures along the longitudinal direction of the packed bed are measured by using a scanning valve and a pressure transducer. After the experiment, injections of gas and powders are stopped quickly. The hold-up of powders is measured by removing the particles isolated in the apparatus by vacuum. The powders are then separated from the packed particles by sieving and are weighed.

\section{Experimental Results}

Fig. 2 shows the change of pressure loss in the packed bed with powder injection at a superficial gas velocity of $0.53 \mathrm{~m} / \mathrm{s}$. By the powder injection, the pressure loss in the packed bed increases. About 10 


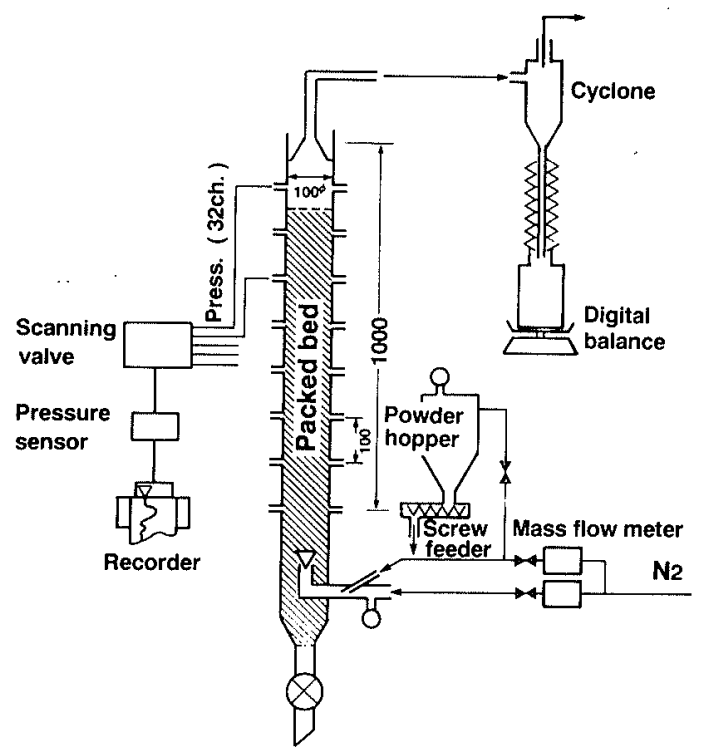

Fig. 1. Experimental apparatus.

Table 1. Characteristics of powders and packed particles.

\begin{tabular}{clcc}
\hline & $\begin{array}{c}\text { Diameter } \\
(\mathrm{mm})\end{array}$ & $\begin{array}{c}\text { Shape } \\
\text { factor }(-)\end{array}$ & $\begin{array}{c}\text { Void } \\
\text { fraction (-) }\end{array}$ \\
\hline \multirow{3}{*}{ Powders } & 0.075 & 0.95 & - \\
& 0.15 & 0.95 & - \\
& 0.212 & 0.95 & - \\
\hline \multirow{3}{*}{ Packed } & 4.8 & 0.85 & 0.33 \\
particles & 3.0 & 1.0 & 0.39 \\
& 3.0 & 0.88 & 0.34 \\
\hline
\end{tabular}

min after, it becomes steady state. At the steady state, it was confirmed that all injected powders flowed out of the top of the packed bed.

The longitudinal distribution of static pressure in the packed bed is shown in Fig. 3. The pressure loss in the lower part of the packed bed is higher than that in the upper part. Therefore, the difference of the static pressures between heights of 200 and 400 $\mathrm{mm}$ was accepted as the experimental value of the pressure loss.

Fig. 4 presents the effect of superficial gas velocity on the pressure loss and the hold-up of powders for gas-powder two phase flow in the packed bed. The packed particles were glass beads of an average diameter of $4.8 \mathrm{~mm}$ and the powders were glass powders of a diameter of $150 \mu \mathrm{m}$. The feed rate of powders was $0.1 \mathrm{~kg} / \mathrm{m}^{2} \mathrm{~s}$. Two phase flow shows higher pressure loss compared with clean gas flow. The hold-up of powders increases below the gas velocity of $0.6 \mathrm{~m} / \mathrm{s}$. As a result, the pressure loss of two phase flow becomes remarkably higher than clean gas flow. Furthermore, blockade, which leads to the rapid increase in pressure loss and the fluidization of the packed bed, occurs at the gas velocity of $0.35 \mathrm{~m} / \mathrm{s}$.

In the previous study, ${ }^{5}$ ) the blockade phenomenon could not be observed. This discrepancy between both experimental results is probably attributed to the difference of the wall effect ${ }^{\text {? }}$ and of the column diameter.

Fig. 5 shows the effect of the powder feed rate on

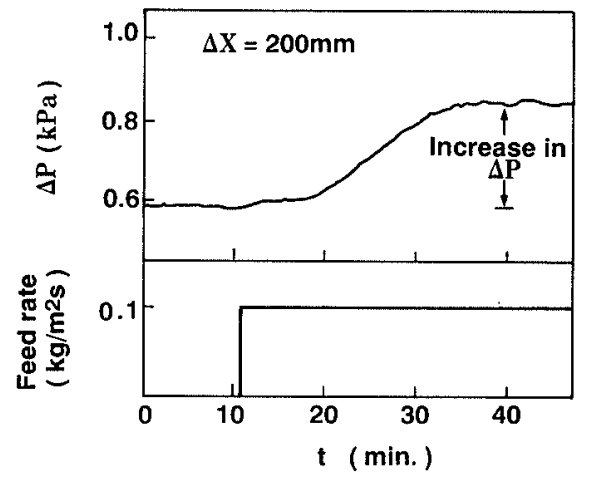

Fig. 2. Change of pressure loss with powder injection.

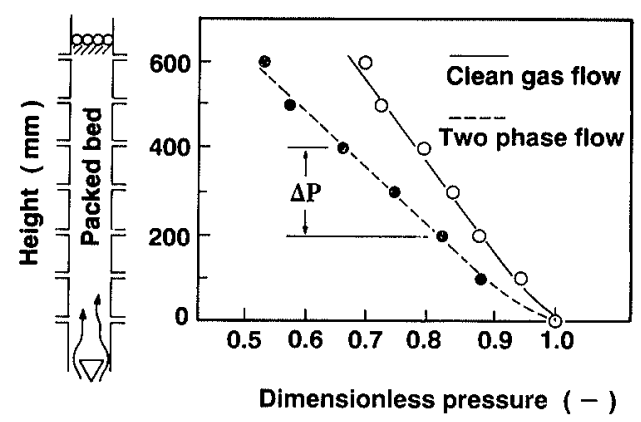

Fig. 3. Longitudinal distribution of static pressure.

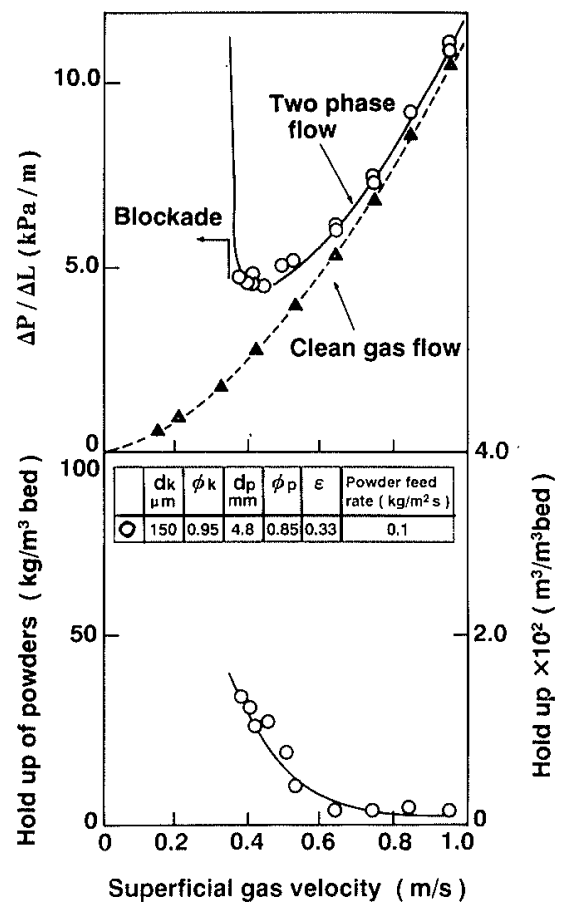

Fig. 4. Effect of superficial gas velocity on pressure loss and powder hold-up for gas-powders two phase flow in a packed bed.

the pressure loss and the hold-up of powders. The pressure loss and the hold-up increases with the increase of the powder feed rate. Blockade occurs at higher gas velocity with the increase of the powder feed rate.

Fig. 6 gives the effect of powder diameter. Three different sizes of glass powders were used including diameters of 212, 150 and $75 \mu \mathrm{m}$. The large powder shows the higher pressure loss and the higher hold-up 


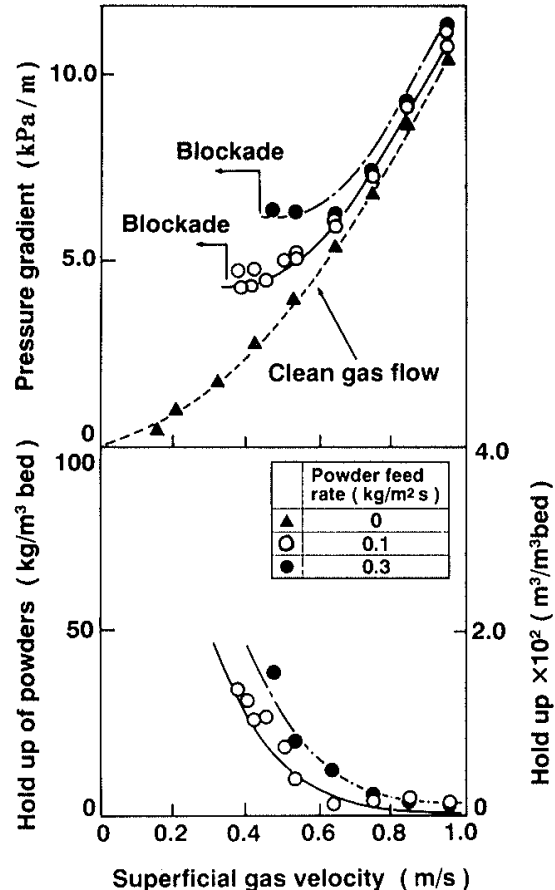

Fig. 5. Effect of powder feed rate on pressure loss and powder hold-up.

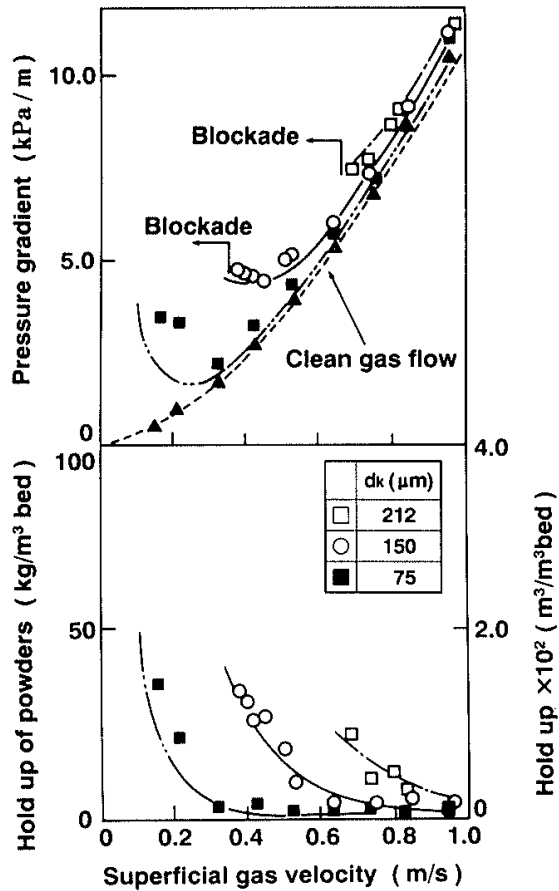

Fig. 6. Effect of powder diameter on pressure loss and powder hold-up.

compared with the small one. In case of the powder diameter of $75 \mu \mathrm{m}$, blockade is not observed. Blockade occurs in other two cases. The gas velocity, at which blockade occurs, increases with the increase of the powder diameter.

The influence of the size and the shape of packed particles on the hold-up is shown in Fig. 7. The following three different types of glass packed particles were used:

(A) An average diameter of $3.0 \mathrm{~mm}$, shape factor of 0.88 and void fraction of 0.34

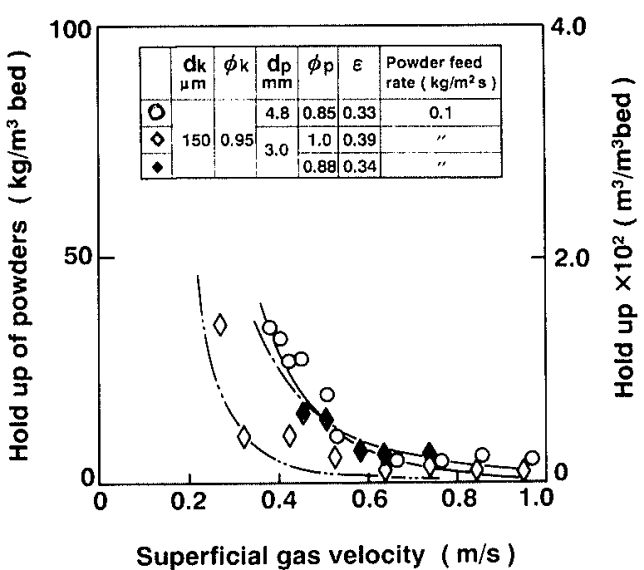

Fig. 7. Effect of size and shape of a packed particle on powder hold-up.

(B) An average diameter of $4.8 \mathrm{~mm}$, shape factor of 0.88 and void fraction of $0.34(\mathrm{O})$

(C) An average diameter of $3.0 \mathrm{~mm}$, shape factor of 1.0 and void fraction of $0.39(\diamond)$

(A) and (B) show similar tendency. In both cases, only a diameter of the packed particle is different. In case of $(\mathrm{C})$, the hold-up of powders is significantly low compared with other two cases. Therefore, following results are obtained:

(1) The diameter of a packed particle affects the hold-up of powders the least.

(2) The hold-up of powders increases with decrease in the shape factor of packed particle and in the void fraction of packed bed.

\section{Mathematical Model of Gas-Powder Two Phase Flow in Packed Beds}

\subsection{Fundamental Equations}

In this study, a one dimensional mathematical model of gas-powder two phase flow in the packed bed is developed to account for the hold-up of powders and the pressure loss in the bed. The model assumes that the voidage of the packed bed is uniformly distributed, the gas and powder flows are steady state and the flow pattern of gas and powders is of plug flow in the bed. Furthermore, there is no cross-sectional concentration variation of powders. The fundamental equations of gas and powders in the packed bed result in the following equations:

\section{Gas Phase}

Continuity equation

$$
d\left(\left(1-\varepsilon_{k}\right) \rho_{a} U_{a}\right) / d x=0
$$

Momentum equation

$$
\begin{aligned}
& d\left(\left(1-\varepsilon_{k}\right) \rho_{a} U_{a} U_{a}\right) / d x \\
& \quad=-d\left(p\left(1-\varepsilon_{k}\right)\right) / d x-\left(F_{g-b}+F_{g-p}\right)
\end{aligned}
$$

\section{Powder Phase}

Continuity equation

$$
d\left(C U_{p}\right) / d x=0
$$


Momentum equation

$$
d\left(C U_{p} U_{p}\right) / d x=F_{g-p}-F_{p-k}
$$

Constitutive equation

$$
C=\varepsilon_{k} \rho_{p}
$$

\subsection{Expressions of Interaction Forces}

The interaction force between gas and packed particles $F_{g-b}$ can be expressed by the Ergun type gas flow resistance as

$$
\begin{aligned}
F_{y-b}= & 150.0 \mu_{a}\left(\frac{1-\varepsilon}{\varepsilon \phi_{p} d_{p}}\right)^{2} \frac{U_{a}}{\varepsilon\left(1-\varepsilon_{k}\right)} \\
& +1.75 \rho_{a}\left(\frac{1-\varepsilon}{\varepsilon \phi_{p} d_{p}}\right)\left(\frac{U_{a}}{\varepsilon\left(1-\varepsilon_{k}\right)}\right)^{2}
\end{aligned}
$$

The total drag force on powders $F_{g-p}$ is the sum of the drag forces of each individual powders as shown in the following equation:

$$
\begin{aligned}
F_{g-p}= & 3 C_{m} \rho_{a}\left|U_{a} /\left(\varepsilon\left(1-\varepsilon_{k}\right)\right)-U_{p}\right|\left(U_{a} /\left(\varepsilon\left(1-\varepsilon_{k}\right)\right)\right. \\
& \left.-U_{p}\right) C / 4 \phi_{k} \rho_{p} d_{k} \quad \ldots \ldots \ldots \ldots \ldots \ldots \ldots \ldots \ldots \ldots \ldots \ldots \ldots \ldots \ldots \ldots \ldots \ldots \ldots \ldots
\end{aligned}
$$

where, $C_{m}$ : the drag coefficient of powders due to gas in the packed bed.

It is assumed that $C_{m}$ can be expressed in terms of the drag coefficient for a single particle according to

$$
C_{m}=F_{0}\left(\varepsilon_{k}\right) C_{d}\left(F_{0}\left(\varepsilon_{k}\right)=\left(1-\varepsilon_{k}\right)^{-4.7}\right)
$$

where, $F_{0}\left(\varepsilon_{k}\right)$ : the Richardson-Zaki's voidage function. ${ }^{8,9)}$

The drag coefficient of a single particle $C_{d}$ can be given by the Stokes flow law as

$$
\begin{aligned}
& R e_{p}<1.0 \quad C_{d}=24.0 / R e_{p} \\
& 1.0<R e_{p}<10^{3} \quad C_{d}=24.0\left(1.0+0.15 R e_{p}^{0.69}\right) / R e_{p} \\
& 10^{3}<\operatorname{Re}_{p} \quad C_{a}=0.44 \\
& R e_{p}=\phi_{k} d_{k}\left|U_{a} /\left(\varepsilon\left(1-\varepsilon_{k}\right)\right)-U_{p}\right|\left(1-\varepsilon_{k}\right) \rho_{a} / \mu_{a}
\end{aligned}
$$

The appropriateness of the expression for $F_{g-p}$ was examined based on the experimental results. Under the assumption that $U_{a}$ is constant in the longitudinal direction of packed bed, $C_{m}$ can be obtained by substituting the experimental values of $\varepsilon_{k}$ and $d p / d x$ into Eq. (2). Fig. 8 shows the relationship betwen $C_{m}$ and $R e_{p}$. It was confirmed that the experimental data could be represented by the Stokes flow law and the Richardson-Zaki's voidage function.

In the previous paper, ${ }^{5)}$ it was shown that $F_{g-p}$ could be given by the Ergun's equation. In the same manner, the modified Reynolds number and the interaction coefficient between gas and powders were calculated from the experimental data. The results are plotted in Fig. 9. Comparison between Figs. 8 and 9 reveals that the Richardson-Zaki's voidage function and the Stokes's law can express $F_{g-p}$ more appropriately compared with the Ergun's equation.

It is assumed that the restraint force of powder motion (the additional pressure loss) $F_{p-k}$ due to (1) the gravitational force of powders and (2) the collision

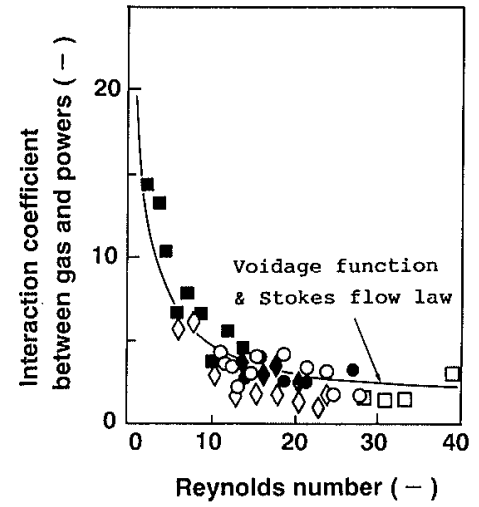

Fig. 8. Relation between Reynolds number $\left(R e_{p}\right)$ and interaction coefficient of gas-powder $\left(C_{m}\right)$.

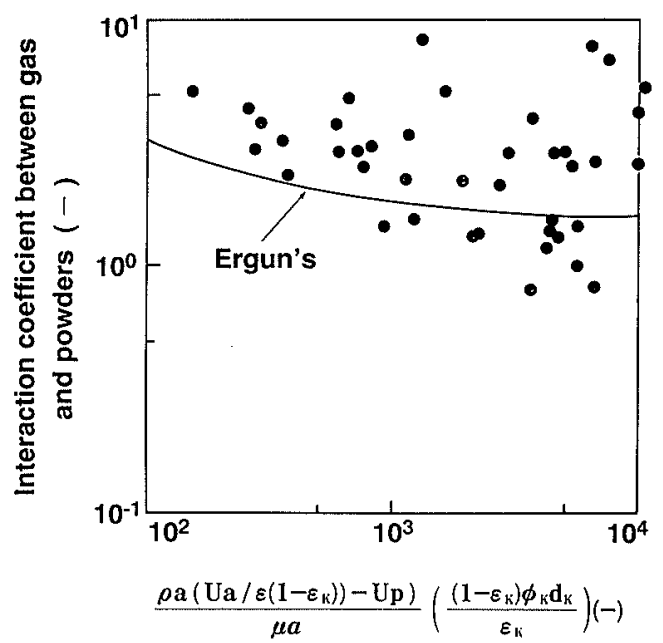

Fig. 9. Comparison of relation between modified Reynolds number and interaction coefficient of gas-powder with Ergun's equation.

and the friction between powders and packed particles can be defined by the Fanning equation as

$$
\begin{array}{r}
F_{p-l t}=C\left(1-\rho_{a} / \rho_{p}\right) g+C U_{p}^{2} f_{k k} /\left(2 D^{*}\right) \\
F_{p-k}=C U_{p}^{2} F k /\left(2 D^{*}\right) \quad \ldots \ldots \ldots \ldots \\
F k=\left(2\left(1-\rho_{a} / \rho_{p}\right) / F r^{2}+f_{k k}\right)
\end{array}
$$

where, $F k$ : the additional pressure loss coefficient.

The quantity $F k$ can be obtained by the following procedures. It is assumed that $U_{a}$ and $U_{p}$ are constant in the longitudinal direction of packed bed. Under this assumption, the substitution of Eqs. (1) to (3) and (5) into Eq. (4) yields

$$
F_{p-k}=-d\left(p\left(1-\varepsilon_{k}\right)\right) / d x-F_{p-b}
$$

In Eq. (16), $U_{p}, \varepsilon_{k}, d p / d x$ and $F k$ are unknown factors. The axial powder velocity $U_{p}$ is calculated from the experimentally obtained powder hold-up $\left(\varepsilon_{k}\right)$ by using the relation

$$
U_{p}=G /\left(A \varepsilon \varepsilon_{k} \rho_{p}\right)
$$

where, $A$ : the cross-sectional area of column $\left(\mathrm{m}^{2}\right)$

$G$ : the powder feed rate $(\mathrm{kg} / \mathrm{s})$.

Therefore, the value of $F k$ can be calculated by substituting the experimental values of the powder hold-up $\left(\varepsilon_{k}\right)$ and the pressure gradient $(d p / d x)$ into 


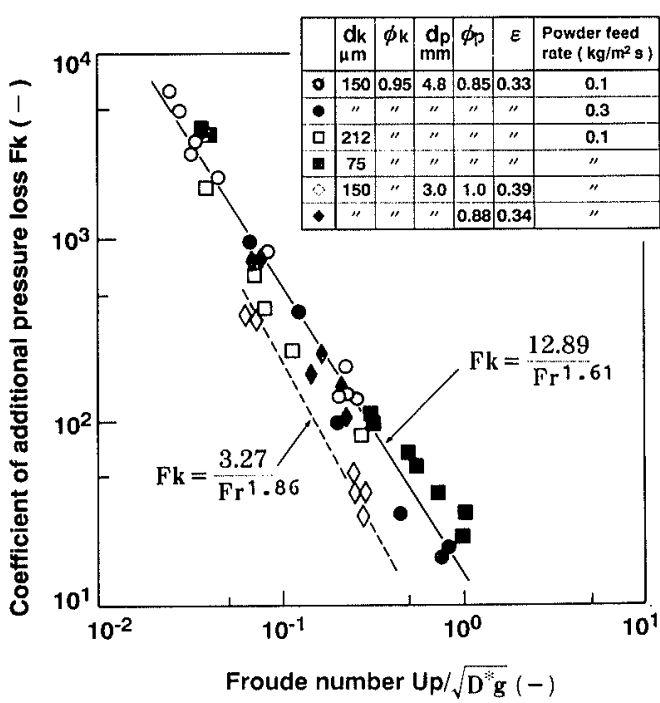

Fig. 10. Relation between Froude number and $F k$.

Eq. (16).

Fig. 10 shows the relationship of $F k$ with the Froude number for various types of packed particles, powders and powder feed rates. It can be seen that the powder diameter, the packed particle diameter and the powder feed rate has practically no effect on $F k$. In this case, the relationship between $F k$ and the Froude number is correlated by the following equation:

$$
F k=12.89 / F r^{1.61}
$$

However, when the shape factor of the packed particle is almost equal to 1.0 and the void fraction of the bed is high, the correlation for $F k$ can be given by

$$
F k=3.27 / F r^{1.83}
$$

This distinction of the correlation for $F k$ is considered to be caused by the difference in the local flow pattern of gas around the packed particle.

\subsection{Appropriateness of the Mathematical Model}

Based on Eqs. (1) to (5) along with Eq. (16) or (17), the holu-up of powders and the pressure loss in the packed bed are calculated. The calculated values are compared with the experimental values as shown in Fig. 11. It can be seen that the mathematical model allows satisfactory prediction of the hold-up of powders and the pressure loss in the packed bed.

\section{Discussion}

\subsection{Pressure Loss for Gas-Powder Two Phase Flow in Packed Beds}

The causes of the increase in the pressure loss between two phase flow and clean gas flow were investigated by using the mathematical model.

Fig. 12 presents the relationship of the superficial gas velocity with the increase in the pressure loss. From this figure, it is found that the causes of the increase in the pressure loss are as follows:

1) the hold-up of powders (the gravitational force of

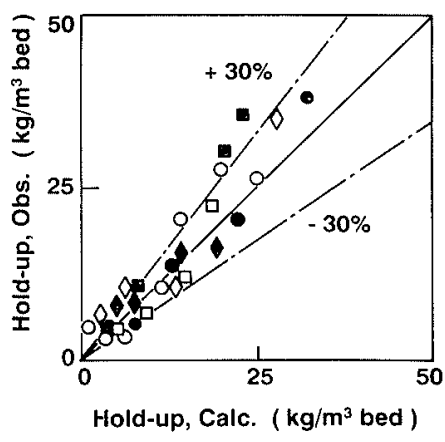

ig. 11. Comparison of experimental data with calculated values.

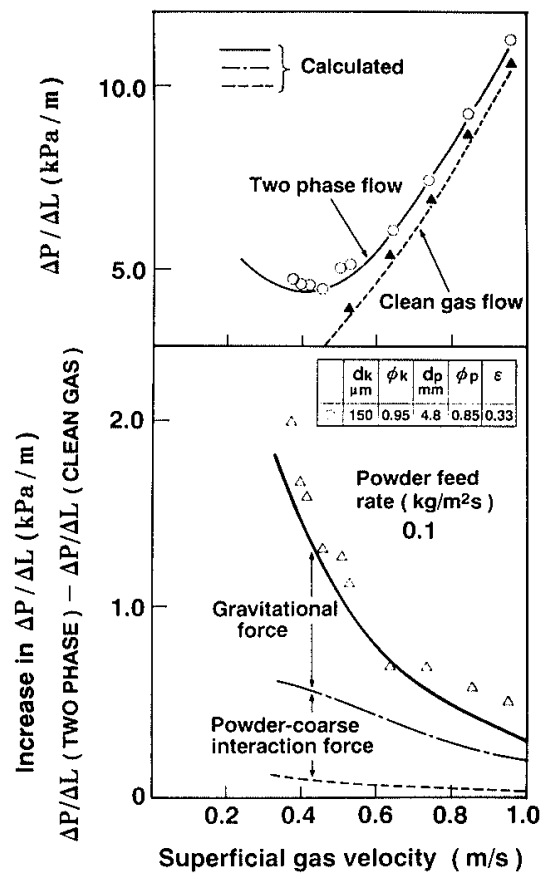

Fig. 12. Cause of increase in pressure loss between two phase flow and clean gas flow.

powders)

2) the interaction force between powders and packed particles due to the friction and the collision

3 ) the increase in a friction force between gas and packed particles caused by the change of gas velocity due to powders

Furthermore, it is confirmed that the increase in the pressure loss is mainly caused by the increase in the hold-up of powders in the region of low gas velocity and by the interaction force between powders and packed particles in the region of high gas velocity.

\subsection{Condition for Blockade}

By the experiment, it was observed that blockade, which led to the rapid increase in pressure loss and the fluidization of a packed bed, occurred at a certain gas velocity. In this study, condition for blockade was examined.

The results are shown in Fig. 13. Abscissa indicates the hold-up of powders and ordinate is the ratio of the powder diameter $\left(d_{k}\right)$ to the hydraulic diameter of the packed bed including powders $\left(D_{\text {eq }}^{*}\right)$. In the 


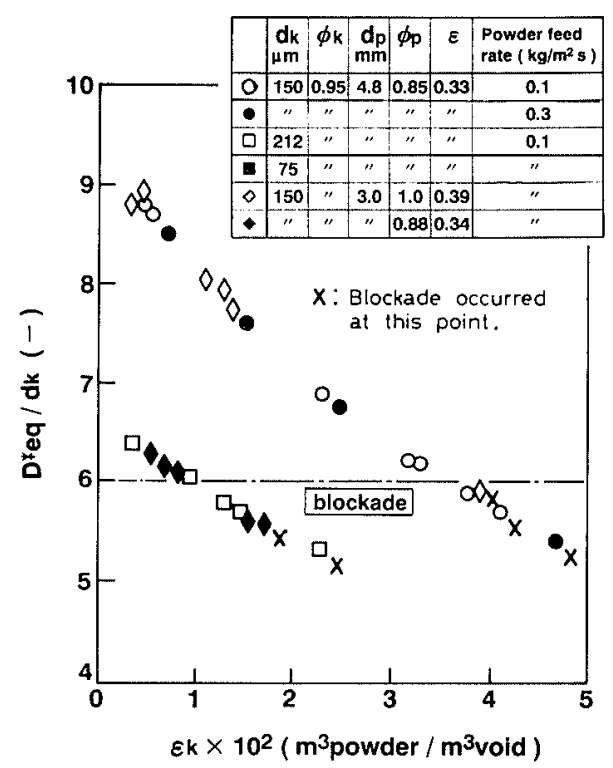

Fig. 13. Condition for blockade.

calculation of $D_{\mathrm{eq}}^{*}$, it is assumed that the packed bed, including powders, is equivalent to that formed by the particle the diameter of which equals to the harmonic mean diameter of the original packed particle and the powder. From this result, it is found that blockade occurs when the ratio of $D_{v q}^{*}$ to $d_{k}$ becomes 5 to 6 . Consequently, blockade occurs at a specific gas velocity where the hydraulic diameter of the packed bed, including powders, is less than 6 times the length of the diameter of powder.

\section{Conclusions}

The flow characteristics of gas-powder two phase flow in packed beds were experimentally examined for clarifying the aerodynamic behavior of powders in a blast furnace. Based on the experimental data, the one dimensional mathematical model was developed. Following results were obtained:

(1) Two phase flow showed higher pressure drop compared to clean gas flow. The increase in pressure loss was mainly caused by the increase in the hold-up of powders in the region of low gas velocity and by the interaction force between powder and packed particles in the region of high gas velocity.

(2) The additional pressure loss coefficient which was defined on the basis of powders in the packed bed was expressed as a function of the Froude number.
This expression, in combination with the mathematical model, allowed satisfactory prediction of the pressure loss and the hold-up of powders in the packed bed.

(3) The blockade occurred at a specific gas velocity where the hydraulic diameter of the packed bed, including powders, was less than 6 times the length of the diameter of powder.

\section{Nomenclature}

$C$ : weight of powder in a unit volume of void $\left(\mathrm{kg} / \mathrm{m}^{3}\right)$

$C_{d}: \quad$ drag coefficient (-)

$C_{m}$ : modified drag coefficient $(-)$

$D^{*}$ : hydraulic diameter of a packed bed (m)

$d_{k}$ : powder diameter $(\mathrm{m})$

$d_{p}$ : diameter of a packed particle $(\mathrm{m})$

Fr: Froude number $(-)=U_{p} / \sqrt{D^{*} g}$

$f_{k / k}$ : interaction coefficient between powders and packed particles $(-)$

$g:$ gravity $\left(\mathrm{m} / \mathrm{s}^{2}\right)$

$p:$ pressure $(\mathrm{Pa})$

$R e_{p}:$ Reynolds number $(-)$

$U_{a}$ : superficial gas velocity $(\mathrm{m} / \mathrm{s})$

$U_{p}:$ powder velocity $(\mathrm{m} / \mathrm{s})$

$\varepsilon$ : void fraction in a packed bed $(-)$

$\varepsilon_{k}$ : powder hold-up in a unit volume of void $(-)$

$\mu_{a}$ : viscosity of gas $(\mathrm{Pa} \cdot \mathrm{s})$

$\rho_{a}:$ density of gas $\left(\mathrm{kg} / \mathrm{m}^{3}\right)$

$\rho_{p}:$ density of a powder $\left(\mathrm{yg} / \mathrm{m}^{3}\right)$

$\phi_{k}$ : shape factor of a powder $(-)$

$\phi_{p}$ : shape factor of a packed particle $(-)$

\section{REFERENCES}

1) M. A. Adeumi and H. Arastoopour: Powder Technology, 48 (1986), 67.

2) H. Arastoopour and D. Gidaspow: Ind. Eng. Chem. Fundam., 18 (1979), 123.

3) L. S. Fan, M. Toda and S. Satija: Powder Technology, 36 (1983), 107.

4) K. Kitano, K. D. Wisecarver, S. Satija and L. S. Fan: Ind. Eng. Chsm. Res., 27 (1988), 1259.

5) H. Yamaoka: Tetsu-to-Hagané, 72 (1986), 403.

6) H. Yamaoka: Tetsu-to-Hagané, 72 (1986), 2194.

7) T. Akiyama and J. Yagi: Bull. Res. Inst. Min. Dressing Met., Tohoku Univ., 46 (1990), 32.

8) J. F. Richardson and W. N. Zaki: Trans. Inst. Chem. Eng., 32 (1954), 35.

9) K. Sakashita and H. Watanabe: J. Soc. Mater. Sci., Jpn., 24 (1975), 682. 